\title{
Chemical tests for phaeochromocytoma
}

\author{
J. KELLEHER, G. WALTERS, R. ROBINSON, AND P. SMITH \\ From the Pathology Department, New Cross Hospital, Wolverhampton, \\ the Group Pathological Laboratory, Warwick, and the \\ R.A.F. Institute of Aviation Medicine, Farnborough
}

SYNOPSIS Urinary catecholamines, 4-hydroxy-3-methoxymandelic acid (V.M.A.), and metadrenalines have been estimated in 39 cases of proven phaeochromocytoma and in many hypertensive patients without phaeochromocytoma. The variation in excretion of these substances is described and their diagnostic significance discussed. Excretion of free catecholamines and metadrenalines showed a proportionately greater increase than of V.M.A. in patients with a phaeochromocytoma, and estimation of the first two appears to be diagnostically more reliable. Hingerty's method for catecholamines appears to be a satisfactory screening test, provided that $90 \mu \mathrm{g}$. is taken as the upper limit of normal, and estimation of metadrenalines is considered to be the best confirmatory test for phaeochromocytoma.

Cases of phaeochromocytoma can be divided into two broad groups from the diagnostic point of view. There are those patients with various symptoms which suggest the diagnosis and those who have no symptoms other than those of hypertension. The latter are clinically indistinguishable from cases of essential hypertension. It is now generally accepted that demonstration of increased secretion of catecholamines is the most reliable method of diagnosis, and this can be done by estimating either catecholamines or their metabolites, 4-hydroxy-3-methoxymandelic acid (V.M.A.) and the 3-0-methyl derivatives of adrenaline and noradrenaline (metadrenalines) in urine. There is, however, no general agreement as to whether estimation of catecholamines or their metabolites gives the best indication of increased catecholamine secretion, and the results are not always easy to interpret.

\section{METHODS}

4-Hydroxy-3-methoxymandelic acid was estimated by two-dimensional paper chromatography (Robinson, Ratcliffe, and Smith, 1959). The spots were compared visually with standards of V.M.A. differing by $0.5 \mu \mathrm{g}$. and ranging from 0.5 to $3 \mu \mathrm{g}$. When values greater than $3 \mu \mathrm{g}$. were obtained, chromatography was usually repeated with a smaller volume of extract so that the amount of V.M.A. fell within the range of standards.

In the most recent cases, V.M.A. was also estimated by the spectrophotometric method of Pisano, Crout, and Abraham (1962).

Received for publication 10 January 1964.
Total metadrenalines were estimated by the method of Pisano (1960). The relative amounts of normetadrenaline and metadrenaline were determined by chromatography (Robinson and Smith, 1962).

Free catecholamines were determined by the method of Hingerty (1957), with the inclusion of additional standards.

\section{RESULTS}

The values taken as normal for the methods used are: V.M.A. less than $5 \mathrm{mg}$./24 hours by chromatography, and less than $7 \mathrm{mg}$. $/ 24$ hours by Pisano's method; total metadrenalines less than $1.3 \mathrm{mg}$. $/ 24$ hours; free catecholamines, less than a standard consisting of pooled normal urine with added noradrenaline equivalent to $90 \mu \mathrm{g}$./ $/ 24$ hours. Hingerty recommended a screening level of $180 \mu \mathrm{g}$./ 24 hours, but, as will be seen later, this may give false negative results. Quantitative determinaation of normetadrenaline and metadrenaline after their chromatographic separation was not attempted.

The V.M.A. results obtained in urines examined by both paper chromatography and Pisano's method are shown in Table I. In general, higher results were obtained with Pisano's method, which also gives higher normal values. Allowing for this, there is good general agreement between the two sets of results, and therefore detailed consideration will be given only to those obtained by chromatography, which are available in every case.

PATIENTS WITH PHAEOCHROMOCYTOMA Urine was 
TABLE I

COMPARISON OF RESULTS FOR V.M.A. OBTAINED WITH TWO DIFFERENT METHODS

\begin{tabular}{|c|c|c|}
\hline Urine & $\begin{array}{l}\text { Chromatographic } \\
\text { (mg./24 hr.) Normal }<5\end{array}$ & $\begin{array}{l}\text { Spectrophotometric } \\
\text { (mg./24 hr.) Normal }<7\end{array}$ \\
\hline 1 & $6 \cdot 8$ & $9 \cdot 1$ \\
\hline 2 & $14 \cdot 0$ & $16 \cdot 3$ \\
\hline 3 & 6.2 & 8.8 \\
\hline 4 & $6 . \overline{8}$ & $12 \cdot 2$ \\
\hline 5 & $12 \cdot 4$ & 17.9 \\
\hline 6 & $10 \cdot 2$ & 6.5 \\
\hline 7 & $14 \cdot 8$ & 17.9 \\
\hline 8 & 10.0 & 15.8 \\
\hline 9 & $18 \cdot 0$ & $21 \cdot 6$ \\
\hline 10 & 22.0 & $19 \cdot 6$ \\
\hline 11 & $73 \cdot 0$ & 105.0 \\
\hline 12 & 20.0 & 23.0 \\
\hline 13 & $42 \cdot 0$ & $45 \cdot 0$ \\
\hline 14 & $27 \cdot 0$ & $32 \cdot 0$ \\
\hline 15 & $12 \cdot 6$ & 15.0 \\
\hline 16 & 28.0 & 34.0 \\
\hline 17 & $22 \cdot 0$ & $26 \cdot 8$ \\
\hline
\end{tabular}

examined from 39 patients in whom a phaeochromocytoma was found. 4-Hydroxy-3-methoxymandelic acid was estimated in all cases, catecholamines in 28 , and total metadrenalines in 20 ; metadrenalines were examined chromatographically in 28 . The results are given in Table II, and where more than one urine was examined from the same patient, only the first three are included in this table. Catecholamines were always increased to at least twice normal in the first urine examined. Total metadrenalines showed a relatively smaller increase in one case while V.M.A. showed a smaller increase in five cases and was actually normal in one; in the latter, the excretion of normetadrenaline was very high.

In some cases many more urines were examined, and the results of all the analyses performed are summarized in Table III. The excretion of total metadrenalines (Pisano) and catecholamines fell below twice the upper limit of normal in some of the later urines, but was never found to be normal, and the frequency of values less than twice normal was lower than for V.M.A. The relatively smaller increase in V.M.A. excretion compared with total metadrenalines is well illustrated by Fig. 1, in which the excretion of total metadrenalines is plotted against that of V.M.A. Most of the values indicate a proportionately greater increase in the excretion of metadrenalines.

While it is well known that secretion of catecholamines is often intermittent, little is known about the variation in phaeochromocytoma patients with sustained hypertension, though it is commonly assumed that secretion is constantly increased. Data from two such cases are presented in Table IV. In both, the excretion of catecholamines was very variable, and on occasion fell below the originally recommended screening level of $180 \mu \mathrm{g}$. per 24

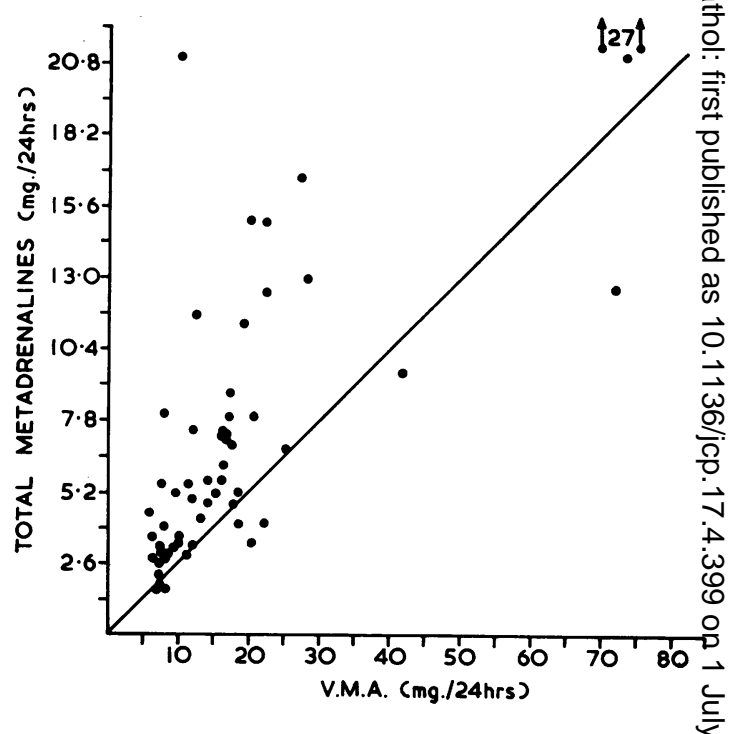

FIG. 1. Relationship between total metadrenalines and V.M.A. in urine from patients with phaeochromocytoms The line is drawn through theoretical points obtained by equating the upper limit of normal for V.M.A. and tota metadrenalines. Points above the line indicate a relative greater increase in excretion of metadrenalines othes than V.M.A.

hours. In neither case did the excretion fall below $90 \mu \mathrm{g}$., which we now take as the screening leveB In case 3 , despite the large fluctuations in cate cholamine excretion, excretion of metabolites was persistently raised, total metadrenalines showing proportionately greater increase than V.M.A. In case 1 metabolites again showed a persistent increase but the levels were such as to be of less value diagnostically than the first few catecholamines.

PATIENTS WITHOUT A PROVEN PHAEOCHROMOCYTOMA Increase secretion of catecholamines was also foun in a number of hypertensive patients in whom $n \overline{\bar{\beta}}$ phaeochromocytoma was located. We have ha\& five cases in which at least three methods reflectefg the increased secretion of catecholamines (Table V) and other cases with increased catecholamines and V.M.A. have been reported elsewhere (Kelleher ang Walters, 1961). The urine values have not usuall exceeded $360 \mu \mathrm{g}$. for catecholamines (four times normal), $10 \mathrm{mg}$. for V.M.A. (twice normal), and $2.5 \mathrm{mg}$. for total metadrenalines (twice normal $\vec{\AA}$ and have usually returned to normal within three of four days after beginning the tests; exceptions to this generalization can occur (example 1, below The difficulty of interpreting results within this range is best illustrated by examples. 
TABLE II

URINE CATECHOLAMINES AND METABOLITES IN PHAEOCHROMOCYTOMA

\begin{tabular}{|c|c|c|c|c|c|c|}
\hline \multirow[t]{2}{*}{ Case } & \multirow{2}{*}{$\begin{array}{l}\text { Free Catechol- } \\
\text { amines }(\mu g . / 24 \text { hr.) } \\
\text { Normal }<90\end{array}$} & \multirow{2}{*}{$\begin{array}{l}\text { V.M.A. } \\
\text { (mg./24 hr.) } \\
\text { Normal }<5.0\end{array}$} & \multirow{2}{*}{$\begin{array}{l}\text { Total Met- } \\
\text { adrenalines } \\
(\mathrm{mg} .124 \mathrm{hr} .) \\
\text { Normal }<1 \cdot 3\end{array}$} & \multicolumn{2}{|c|}{ Chromatography of Metadrenalines } & \multirow[t]{2}{*}{ Site of Tumour } \\
\hline & & & & Normetadrenaline & Metadrenaline & \\
\hline 1 & $\begin{array}{l}700 \\
700 \\
700\end{array}$ & $\begin{array}{l}8 \cdot 0 \\
7 \cdot 5 \\
7 \cdot 5\end{array}$ & $\begin{array}{l}1 \cdot 6 \\
1 \cdot 6 \\
1 \cdot 7\end{array}$ & $\begin{array}{l}\bumpeq 8 \times \text { normal } \\
- \\
-\end{array}$ & $\begin{array}{l}\text { Normal } \\
\text { - }\end{array}$ & Adrenal \\
\hline 2 & $\begin{array}{r}200 \\
1,200 \\
400\end{array}$ & $\begin{array}{l}25 \\
18 \\
20\end{array}$ & $\begin{array}{l}6 \cdot 6 \\
4 \cdot 7 \\
3 \cdot 4\end{array}$ & $\begin{array}{l}>8 \times \text { normal } \\
>8 \times \text { normal } \\
>8 \times \text { normal }\end{array}$ & $\begin{array}{l}\text { Normal } \\
\text { Normal } \\
\text { Normal }\end{array}$ & Extra-adrenal \\
\hline 3 & $\begin{array}{l}400 \\
400 \\
250\end{array}$ & $\begin{array}{l}20 \\
19 \\
28\end{array}$ & $\begin{array}{r}7 \cdot 9 \\
5 \cdot 2 \\
13 \cdot 0\end{array}$ & $\begin{array}{l}>8 \times \text { normal } \\
>8 \times \text { normal } \\
>8 \times \text { normal }\end{array}$ & $\begin{array}{l}\text { Normal } \\
\text { Normal } \\
\text { Normal }\end{array}$ & Extra-adrenal \\
\hline 4 & 900 & 17 & $7 \cdot 9$ & $>8 \times$ normal & Normal & Extra-adrenal \\
\hline 5 & $\begin{array}{r}1,000 \\
>1,000\end{array}$ & $\begin{array}{l}27 \\
22\end{array}$ & $\begin{array}{l}16 \cdot 6 \\
15 \cdot 0\end{array}$ & $\begin{array}{l}>8 \times \text { normal } \\
-\end{array}$ & Increased & Adrenal \\
\hline 6 & $>180$ & 6.0 & $4 \cdot 5$ & $>8 \times$ normal & Normal & Adrenal \\
\hline 7 & $>180$ & 8.0 & $8 \cdot 0$ & $>8 \times$ normal & Normal & Adrenal \\
\hline 8 & $>1,000$ & $10 \cdot 0$ & $21 \cdot 0$ & $>8 \times$ normal & Normal & Adrenal \\
\hline 9 & $E^{540}$ & $\begin{array}{c}\overline{8} \cdot 5 \\
19\end{array}$ & $\begin{array}{l}\overline{2 \cdot 9} \\
4 \cdot 0\end{array}$ & $\begin{array}{l}\overline{-} \\
>8 \times \text { normal }\end{array}$ & $\overline{\bar{N}}$ & Extra-adrenal \\
\hline 10 & 3,000 & 42 & $9 \cdot 5$ & $>8 \times$ normal & Normal & Extra-adrenal \\
\hline 11 & $>1,000$ & $11 \cdot 5$ & $5 \cdot 5$ & $>8 \times$ normal & Normal & Adrenal \\
\hline 12 & $>1,000$ & $12 \cdot 6$ & $11 \cdot 7$ & $>8 \times$ normal & Normal & Adrenal \\
\hline 13 & 3,000 & 75 & $27 \cdot 0$ & $>8 \times$ normal & Increased & Adrenal (malignant) \\
\hline 14 & $>1,000$ & 73 & $21 \cdot 2$ & $>8 \times$ normal & Normal & Adrenal \\
\hline 15 & $>360$ & 72 & $12 \cdot 7$ & - & - & - \\
\hline 16 & $\begin{array}{l}360 \\
360 \\
360\end{array}$ & $\begin{array}{l}9 \cdot 5 \\
9 \cdot 5 \\
6 \cdot 3\end{array}$ & $\begin{array}{l}5 \cdot 7 \\
5 \cdot 2 \\
3 \cdot 6\end{array}$ & $\begin{array}{l}\text { Slight increase } \\
\text { - }\end{array}$ & $\begin{array}{l}>8 \times \text { normal } \\
-\end{array}$ & Adrenal \\
\hline 17 & $>1,000$ & 16 & - & - & - & Adrenal \\
\hline 18 & $>1,000$ & $>10$ & $16 \cdot 0$ & $>8 \times$ normal & Normal & Adrenal \\
\hline 19 & $\begin{array}{l}>1,000 / \mathrm{g} . \\
\text { creatinine }\end{array}$ & $\begin{array}{l}>30 / g \\
\text { creatinine }\end{array}$ & $\begin{array}{l}>21 / \mathrm{g} \text {. } \\
\text { creatinine }\end{array}$ & $>8 \times$ normal & $>8 \times$ normal & Adrenal (bilateral) \\
\hline 20 & $\begin{array}{l}2,000 \\
2,700\end{array}$ & $\begin{array}{l}22 \\
20\end{array}$ & $\begin{array}{l}12 \cdot 7 \\
15 \cdot 1\end{array}$ & Slight increase & $\begin{array}{l}>8 \times \text { normal } \\
-\end{array}$ & Adrenal \\
\hline 21 & $>1,000$ & 16 & - & 一 & - & 一 \\
\hline 22 & $>1,000$ & 20 & - & $>8 \times$ normal & Normal & $\begin{array}{l}\text { Adrenal and extra- } \\
\text { adrenal }\end{array}$ \\
\hline 23 & $\begin{array}{c}\text { Increased by } \\
\text { bio-assay }\end{array}$ & 15 & - & - & - & - \\
\hline 24 & $>1,000$ & 16 & - & $>8 \times$ normal & Increased & $\begin{array}{l}\text { Adrenal and extra- } \\
\text { adrenal }\end{array}$ \\
\hline 25 & 1,200 & $9 \cdot 0$ & - & $>8 \times$ normal & Normal & Adrenal \\
\hline 26 & 一 & $\begin{array}{c}2 \cdot 2 / g . \\
\text { creatinine }\end{array}$ & - & $>8 \times$ normal & Normal & Adrenal \\
\hline 27 & 2,600 & $>20$ & - & $>8 \times$ normal & Normal & Adrenal (bilateral) \\
\hline 28 & 3,000 & $>20$ & - & $>8 \times$ normal & Normal & Adrenal \\
\hline 29 & 一 & $>10$ & - & $>8 \times$ normal & Normal & Adrenal \\
\hline 30 & - & $>10$ & - & $>8 \times$ normal & Normal & - \\
\hline 31 & - & $>10$ & - & $>8 \times$ normal & Normal & Adrenal \\
\hline 32 & 3,500 & 12 & $4 \cdot 3$ & $>8 \times$ normal & Normal & Adrenal \\
\hline $33-39$ & - & $>10$ in all cases & - & - & - & - \\
\hline
\end{tabular}

TABLE III

EXCRETION OF CATECHOLAMINES AND METABOLITES IN ALL URINES EXAMINED FROM PROVEN CASES OF PHAEOCHROMOCYTOMA

Catecholamines

V.M.A.

Total Metadrenalines

Metadrenalines by

Chromatography

\begin{tabular}{lccr}
\hline No. of specimens examined & 64 & 70 & 60 \\
Excretion + & 61 & 54 & 46 \\
Excretion t & 3 (from case 3) & 15 (from 6 cases) & 56 \\
Excretion normal & 0 & 1 & 4 (from case 1) \\
\hline
\end{tabular}

$++=$ excretion increased to at least twice the upper limit of normal

$+\quad=$ excretion increased, but less than twice the upper limit of normal 
TABLE IV

VARIATION IN EXCRETION OF CATECHOLAMINES AND METABOLITES IN TWO PATIENTS WITH PHAEOCHROMOCYTOMA AND PERSISTENT, SYMPTOMLESS HYPERTENSION

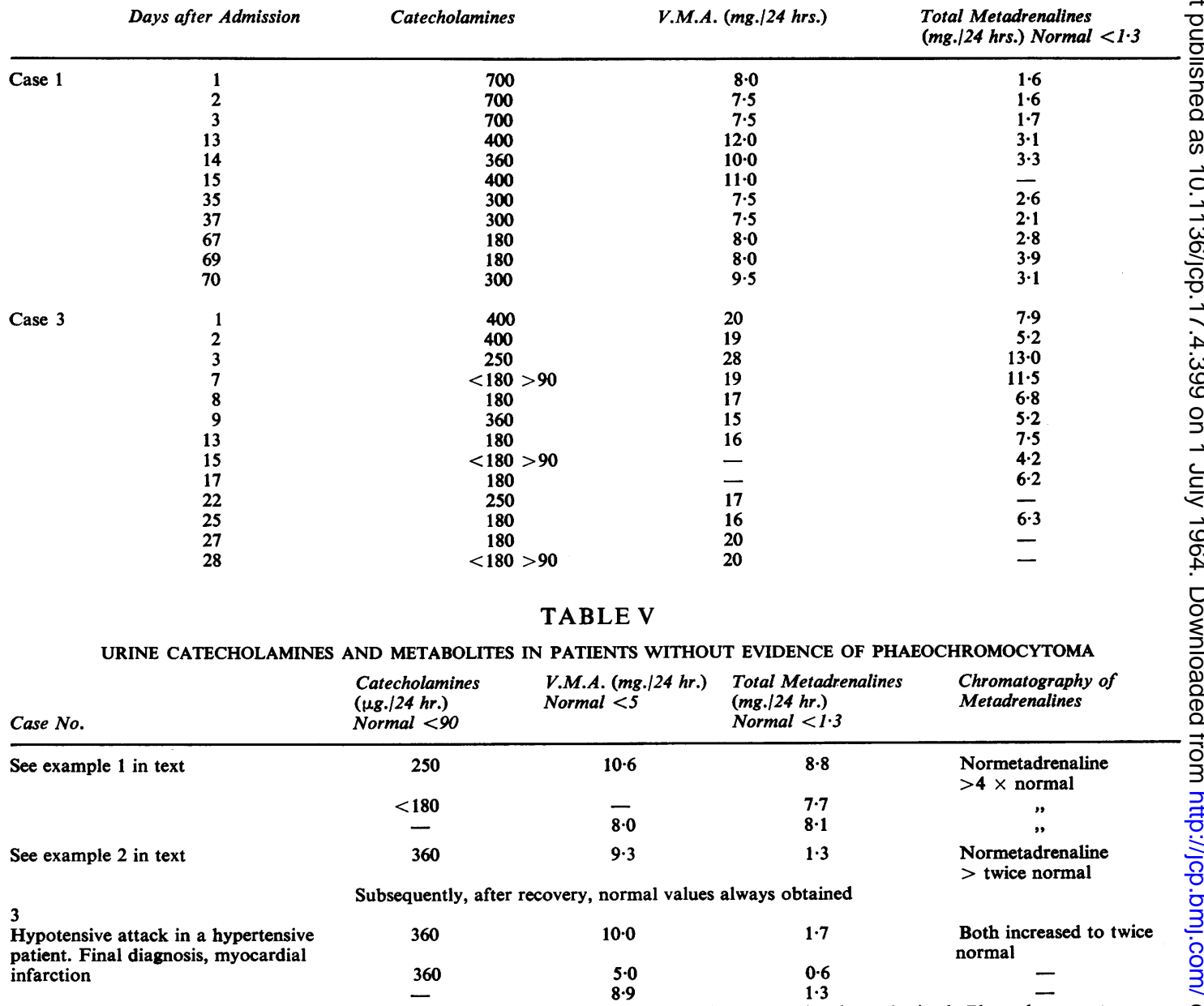

Subsequently, despite return of hypertension, normal values obtained. Phaeochromocytoma now음 considered very improbable

4
Hypertension

5

Hypertension: paroxysmal left ventricular failure and sweating 6 months. Blood pressure $260 / 160 \mathrm{~mm}$. Hg. With bed rest, all symptoms subsided and blood pressure fell to $160 / 105 \mathrm{~mm}$. Hg. Histamine had no effect.

$$
250
$$

8.8

Subsequently, normal values were obtained

$\begin{array}{rcc}200 & - & 1.6 \\ 200 & - & 1.4 \\ 250 & - & 1.9 \\ <90 & 2.0 & 0.8 \\ <90 & 2.0 & 0.8 \\ 180 & 2.0 & 1.8\end{array}$

Subsequently, blood pressure rose to former levels but chemical tests were repeatedly normal
Example 1 A man aged 63 years was admitted with myocardial infarction and carcinoma of the bronchus. Two days later, he suddenly experienced palpitations, associated with a supraventricular tachycardia of $200 /$ minute and a rise in blood pressure from $115 / 80$ to $300 / 180 \mathrm{~mm} . \mathrm{Hg}$. Intravenous phentolamine had no effect, and procaine amide and digoxin were given. Over the next 18 hours, the blood pressure fell to 80/40 $\mathrm{mm} . \mathrm{Hg}$ and rose again to $110 / 70 \mathrm{~mm} . \mathrm{Hg}$. Urine $\triangle$ collected over 24 hours showed catecholamines ofo approximately $250 \mu \mathrm{g} . / 24$ hours, V.M.A. $10.6 \mathrm{mg}$., and total metadrenalines $8.8 \mathrm{mg}$; paper chromatographyO 
indicated a great increase in noradrenaline secretion but no increase in adrenaline. There were no further attacks. Death occurred six days later, and necropsy revealed myocardial infarction, extensive infiltration of the mediastinum and myocardium by bronchial carcinoma, but no phaeochromocytoma was found; the left adrenal contained a small metastasis.

Example 2 A man aged 30 years underwent partial gastrectomy for duodenal ulcer; the operation was uneventful. A few hours postoperatively the pulse rate rose to $160 / \mathrm{min}$. (sinus rhythm) and the blood pressure to $250 / 140 \mathrm{~mm} . \mathrm{Hg}$. A laparotomy revealed only a small amount of blood which was considered inadequate to explain his condition. A phaeochromocytoma was suspected, but intravenous phentolamine had no effect. Procaine amide and digoxin were given, and the attack subsided about 36 hours later. Urine collected during this period showed the 24-hour excretion of catecholamines to be $360 \mu \mathrm{g}$., V.M.A. $9.6 \mathrm{mg}$., and total metadrenalines $1.3 \mathrm{mg}$.; chromatography showed a slight increase of normetadrenaline. The patient has remained well and normotensive since, with repeatedly normal excretion of catecholamines and metabolites. Although a phaeochromocytoma cannot be excluded, it appears unlikely.

\section{DISCUSSION}

Although the excretion of catecholamines in the first urine examined from phaeochromocytoma patients was at least $180 \mu \mathrm{g} . / 24$ hours, the fact that some of the later urines gave values less than this while the excretion of metabolites remained high, indicates that there is a risk of false negative results with this method. For this reason, the lower screening limit of $90 \mu \mathrm{g}$., which is nearer the normal values found with quantitative methods, should be used. In none of the present series was a value of less than $90 \mu \mathrm{g}$. obtained in the presence of other evidence that the tumour was secreting. Litchfield and Peart (1956) described one case in which catecholamines, determined by bio-assay, were not raised even after a paroxysm, but it is not known whether excretion of metabolites was raised in this case.

Excretion of total metadrenalines was raised in every urine examined, though again, in some of them the values were only slightly above normal (Table IV). We are aware of only one case reported with normal excretion of total metadrenalines associated with raised excretion of catecholamines (Crout, Pisano, and Sjoerdsma, 1961). Chromatographic separation of normetadrenaline and metadrenaline in our cases always showed a large rise in one or other. The apparent discrepancy between the values for total metadrenalines and those for the individual metadrenalines obtained by paper chromatography may be due to variation in the pro5 portion of the adrenaline derivative, and to the spectrophotometric method being less specific; Crout et al. (1961) consider that values below $2 \mathrm{mg}$. $/ 24 \mathrm{hr}$. with the latter are not quantitatively reliable.

4-Hydroxy-3-methoxymandelic acid was increased in all except one case, but the increase was generally less than that of the metadrenalines. This is a low incidence of negative results, but Crout et al. found a normal V.M.A. level in three out of 23 cases of phaeochromocytoma in which there was evidence that secretion of catecholamines was increased.

A normal result may obviously be obtained with all of these methods if the tumour is in a nonsecreting phase. There is also the slight possibility of obtaining a normal result with one method when the others indicate increased secretion. The chances of this happening in patients without paroxysmal symptoms can be reduced by examining more than one urine as a routine, as this will make some allowance for the day-to-day variation in excretion illustrated in Table IV.

A much greater diagnostic difficulty arises from the fact that excretion of catecholamines and their metabolites may be increased in the absence of a phaeochromocytoma. The values for catecholamines, V.M.A., and total metadrenalines found in such cases overlap the lower levels found in phaeochromocytoma. The reasons for this are not clearly defined, but it is known that various forms of physical and emotional stress can give rise to a six-fold increase in catecholamine secretion (Elmadjian, 1959). In our experience it may be very difficult to interpret increases up to $360 \mu \mathrm{g}$. (four times normal) for catecholamines determined by Hingerty's method, and up to twice normal for V.M.A. and total metadrenalines. Values greater than these are highly suggestive of a catecholamine-secreting tumour, though they are not necessarily diagnostic, as illustrated by example 1 above; moreover two patients of Bollman, Flock, Roth, and Kvale (1960) were finally considered not to have a phaeochromocytoma even though their V.M.A. excretion was 12 and $15 \mathrm{mg}$. per 24 hours respectively.

The method most likely to give results diagnostic of phaeochromocytoma is clearly the one which consistently gives the greatest increase. Crout $e t$ al. (1961) found in 23 phaeochromocytomas that catecholamine excretion, as determined by spectrofluorimetry, usually showed the greatest proportional increase, and they considered this the most reliable diagnostic method. However, because of the technical complexity of the methods for quantitative estimation of catecholamines they preferred estimation of metabolites for routine use. They recommend 
estimation of total metadrenalines which they found gave results diagnostically more reliable than those of V.M.A.; excretion of the latter showed the smallest increase in most cases. The data in Fig. 1 confirm their finding that excretion of metadrenalines usually shows a proportionately greater increase than that of V.M.A., but we emphasize that this relationship is variable.

When results obtained with one method fall within the 'false positive' range, further information can be obtained by proceeding to further tests and also by analysing more urines (Table IV). So far, chromatographic analysis of metadrenalines has always shown a striking increase of one component in phaeochromocytoma, and, with the exception of example 1 above, a much less striking increase in other cases. As this method has not yet been widely used it is too early to say whether it will always be diagnostically superior to other methods, but at present it appears to be the most reliable test. It is unfortunate that it is not suitable for routine use, as it is also valuable for studying the excretion of amines other than metadrenaline and normetadrenaline (Robinson and Smith, 1962).

In all cases of phaeochromocytoma it is desirable to know whether the tumour secretes much adrenaline, because of the possibility of cardiac dysrhythmias during operation. Furthermore, Hunter, Marshall, and Oram (1963) assayed urinary adrenaline and noradrenaline separately in 14 cases, and believe that tumours which secrete only noradrenaline are likely to be para-aortic, while those which secrete adrenaline are likely to be adrenal. Where facilities are not available for the separate estimation of adrenaline and noradrenaline, the same information can be obtained by chromatographic analysis of the metadrenalines, but in our experience the results of such analysis are of limited value in indicating the probable site of the tumour (Table II). Contrary to the findings of Hunter et al. (1963), in 17 out of 22 cases with increased excretion of normetadrenaline only, the tumour was in the adrenal medulla. In the six cases with increased metadrenaline our findings agreed with those of Hunter et al., and all had a tumour in the adrenal medulla. In one of them, however, there was a second tumour which was extra-adrenal.
For routine screening of hypertensive patients it is

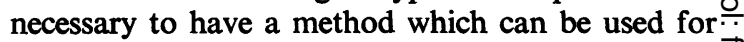
large numbers of urines, and which will not give $\vec{\Rightarrow}$ false negative results. We have found the screening test for increased urinary catecholamines (Hingerty) $\frac{\mathrm{C}}{\partial}$ to be very useful for this purpose. We consider, however, that in order to eliminate false negative results, a level of approximately $90 \mu \mathrm{g} . / 24 \mathrm{hr} . \stackrel{\varrho}{\Omega}$ should be regarded as the screening limit. Values ${ }^{\text {क }}$ greater than this should be investigated further by $\vec{\circ}$ other methods. Some drugs interfere with chemical estimation of catecholamines (Bollman et al., 1960), $\stackrel{\omega}{\circ}$ and alpha-methyldopa gives high results for at least five days after stopping the drug. In cases where? drugs cannot be withheld, or where other fluorescent. substances interfere, estimation of metabolites is $\vec{\omega}$ necessary. The numbers of the latter can be kept $\varrho$ small by using the Hingerty method routinely as theo screening test.

Where large numbers of urines are not examined, $\vec{c}$ Pisano's method for total metadrenalines appears to be the method of choice for routine use. It appears $\vec{\varphi}$ to give more helpful results than estimation of V.M.A., and its estimation is easier. Confirmation by other methods, is of course, still required wheno values are not much increased.

We wish to thank our many colleagues who have sent us气

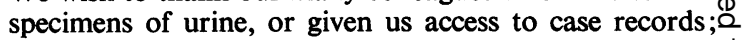
also Dr. T. M. Curran and Dr. F. J. Pick for the clinical and necropsy findings in example 1 , and Wing Com- 3 mander P. Robertson for the details of example 2. We? thank the Director General of the R.A.F. Medicato Services for permission to publish, and Dr. G. K. McGowan for advice on the presentation of our data.

\section{REFERENCES}

Bollman, J. L., Flock, E. V., Roth, G. M., and Kvale, W. F. (1960) J. Lab. clin. Med., 56, 506.

Crout, J. R., Pisano, J. J., and Sjoerdsma, A. (1961). Amer. Heart J., 61, 375.

Elmadjian, F. (1959). Pharmacol. Rev., 11, 409.

Hingerty, D. (1957). Lancet, 1, 766.

Hunter, R. B., Marshall, P. B., and Oram, F. Jean. (1963). Quart J Med., 32, 225.

Kelleher, J., and Walters, G. (1961). Lancet, 2, 1312.

Litchfield, J. W., and Peart, W. S. (1956). Ibid., 2, 1283.

Pisano, J. J. (1960). Clin. chim. Acta, 5, 406.

Robinson, R., Ratcliffe, J., and Smith, P. (1959). J. clin. Path., 12, 541

—, and Smith, P. (1962). Clin. chim. Acta, 7, 29. 